\title{
Guest editorial for EMMSAD'2020 special section
}

\author{
Iris Reinhartz-Berger ${ }^{1}$. Jelena Zdravkovic ${ }^{2}$
}

Received: 2 June 2021 / Accepted: 14 June 2021 / Published online: 22 June 2021

(c) The Author(s), under exclusive licence to Springer-Verlag GmbH Germany, part of Springer Nature 2021

The EMMSAD (Exploring Modeling Methods for Systems Analysis and Development) conference series organized 25 events from 1996 to 2020, associated with CAISE (Conference on Advanced Information Systems Engineering). From 2009, EMMSAD has become a two-day working conference. From 2017, EMMSAD best papers are invited to submit extended versions for considering their publication in the Journal of Software and Systems Modeling (SoSyM). The main topics of the EMMSAD series have the focus on models and modeling methods for software and information systems development. These are organized into five tracks: (1) Foundations of Modeling \& Method Engineering; (2) Enterprise, Business Process \& Capability Modeling; (3) Information Systems \& Requirements Modeling; (4) Domain-Specific \& Ontology Modeling; and (5) Evaluation of Modeling Approaches. The aims, topics, and history of EMMSAD can be also found on its website at http://www. emmsad.org/.

\section{Scope}

This special section follows the 25th edition of the EMMSAD series, organized in conjunction with CAISE'20 virtually (originally planned in Grenoble, France), June 2020. The program of this edition included 15 accepted papers: three related to requirements \& method engineering, three on enterprise \& business modeling, three on evaluation-related research, three referred to domain-specific modeling, and the last three to software-related modeling. The mosaic of these papers, which have been published in [1], show the variety of current and novel researches in the modeling area of information systems and software analysis and development. Top-scored papers were invited to submit

\footnotetext{
Iris Reinhartz-Berger

iris@is.haifa.ac.il

1 University of Haifa, Haifa, Israel

2 Stockholm University, Stockholm, Sweden
}

extended and enhanced versions for consideration in this special section of Software and System Modeling (SoSyM) journal.

\section{The papers selected for this special section}

This special section presents four articles. The first three are among those accepting our invitation to submit extended versions of their EMMSAD'2020 papers. The newly submitted papers went through a rigid review process of two to three rounds. Below is the list of papers:

1. Roman Lukyanenko, Oscar Pastor, and Veda Storey. "Foundations of information technology based on Bunge's systemist philosophy of reality" - the article introduces Bunge's Systemist Ontology (BSO) and compares it to the well-known Bunge-Wand-Weber (BWW) ontology. It further suggests ontology studies and identifies research questions relevant to the conceptual modeling community and other areas of information technology.

2. Ben Roelens and Dominik Bork. "A technique for evaluating and improving the semantic transparency of modeling language notations" - the article proposes a design technique that, based on iterative development and evaluation tasks, steers the notation design process for modeling languages toward semantic transparency. The approach is aimed to be applied to arbitrary modeling languages to allow easy integration into existing modeling language engineering methodologies.

3. Rick Gilsing, Anna Wilbik, Paul Grefen, Oktay Turetken, and Baris Ozkan. "Defining business model key performance indicators using intentional linguistic summaries"-the article proposes design, formalization, and evaluation of a method for defining KPIs to support business model evaluation, by leveraging theory on linguistic summarization which can be catered for early phases of business model innovation. 
The fourth article is an invited "expert voice" providing a research commentary by modeling experts. Following Jordi Cabot's keynote at EMMSAD'2019 on "Modeling and AI: friends or foes?", we invited him and his team to write a paper to this special section. This paper also relates to the interplay between modeling and AI.

4. Elena Planas, Gwendal Daniel, Marco Brambilla, and Jordi Cabot. "Towards a model-driven approach for multi-experience AI-based user interfaces"-the article explores the application of model-driven techniques to the development of software applications embedding a multi-experience interface. It further discusses how raising the abstraction level at which these interfaces are defined enables a faster development and a better deployment and integration of each interface with the rest of the software system.

Acknowledgements We wish to thank the PC committee of EMMSAD'2020 and especially the following reviewers for their timely and valuable reviews during the review process for this special section: Dominik Bork, Drazen Brdjanin, Tony Clark, Peter Green, Martin Henkel, Andreas Opdahl, Marcela Ruiz, Kurt Sandkuhl, Monique Snoeck, Janis Stirna, Ron Weber, and Anna Zamansky.

We would also like to thank the track chairs for their help in EMMSAD advertising and decision-making: Jolita Ralyté \& Janis Stirna for track 1, Jānis Grabis \& Paul Grefen for for track 2, Oscar Pastor \& Marcela Ruiz for track 3, Dimitris Karagiannis \& Arnon Sturm for track 4, and Agnes Koschmider \& Geert Poels for track 5.

Special thanks go to the organizing committee of CAiSE 2020, IFIP WG8.1, the Editors-in-Chief of the Journal of Software and Systems Modeling (SoSyM) - Jeff Gray and Bernhard Rumpe, SoSyM Assistant Editor - Martin Schindler, and EMMSAD advisory committee - John Krogstie and Henderik A. Proper.

Finally, our gratitude goes to all authors of the selected papers who made this special section possible in the challenging times of global pandemic.

\section{Reference}

1. Nurcan, S., Reinhartz-Berger, I., Soffer, P., Zdravkovic, J. (Eds.): Enterprise, Business-Process and Information Systems Modeling: 21st International Conference, BPMDS 2020, 25th International Conference, EMMSAD 2020, Held at CAISE 2020, June 8-9, 2020, Proceedings, vol. 387. Springer (2020)

Publisher's Note Springer Nature remains neutral with regard to jurisdictional claims in published maps and institutional affiliations.

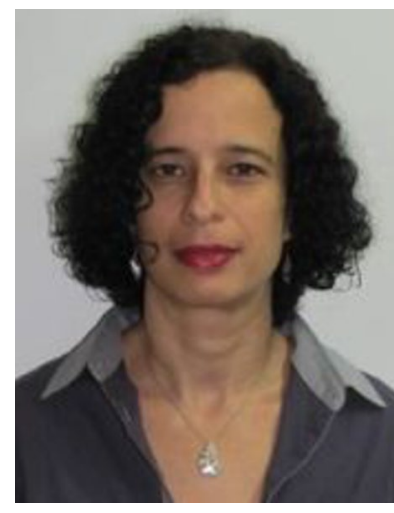

Iris Reinhartz-Berger is the chair of the Department of Information Systems, University of Haifa, Israel. She received her $\mathrm{MSc}$ and $\mathrm{PhD}$ in Information Management Engineering from the Technion - Israel Institute of Technology, and her BSc in computer science and applied mathematics from the Technion - Israel Institute of Technology. Her research interests include conceptual modeling, domain analysis, modeling languages and techniques for analysis and design, and requirements engineering. She co-organized a series of domain engineering workshops, in conjunction with the CAiSE conference, and co-edited a book entitled "Domain Engineering: Product Lines, Languages, and Conceptual Models." She co-chairs EMMSAD - Exploring Modeling Methods for Systems Analysis \& Development since 2017. She is in the Editorial Board of Software \& Systems Modeling (SoSyM), Data \& Knowledge Engineering (DKE), Requirements Engineering (RE), and Business \& Information Systems Engineering (BISE) journals.

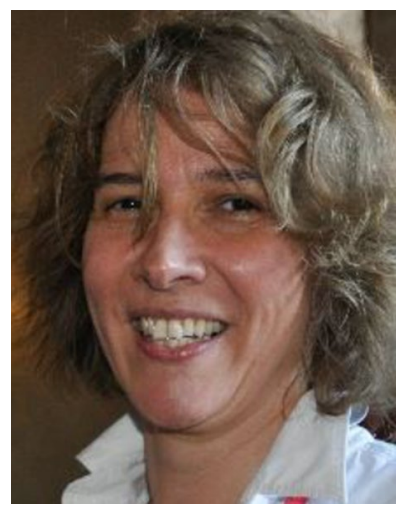

Jelena Zdravkovic is a Professor and Vice Head of Computer and Systems Sciences (DSV) department at Stockholm University. She has a $\mathrm{PhD}$ in Computer and Systems Sciences at The Royal Institute of Technology (KTH), as well as the MBA degree in E-commerce. Jelena's research activities include requirements engineering and capabilitydriven development. Jelena has published around 100 refereed papers in international conferences and scientific journals on the topics of requirements engineering and capability-driven development. She is in the Editorial Board of Springer BISE and RE Journals, as well as a regular reviewer and guest editor for a number of other international journals including several of Springer, Elsevier's Journal of Systems and Software and Information and Software Technology Journal, and IEEE Computing. Jelena has organized a number of international conferences and workshops in the IS Engineering discipline, and she serves in the program committees of many of them. 